\title{
Meeting report: musculoskeletal medicine with a focus on pain
}

\author{
April 22-25, 2010 Loews Hotel, 126 West Street, Annapolis, MD 21401, USA
}

\author{
Stephanie Wilson
}

Published online: 12 June 2010

(C) Humana Press 2010

In April 2010, a record-breaking AOCPMR Mid Year Meeting was held in Annapolis, MD. In all, 90 attending physicians and residents and 170 medical students filled the Loews Hotel as Brian Kahan chaired our largest-attended AOCPMR conference to date.

Side by side in the Grand Ball Room of the Hotel, simultaneous lectures were delivered to both the physicians and medical students. The dialogue and the exchange of advice and ideas exemplify why the AOCPMR sets the bar as the professional organization for others to emulate.

Program chair Brian Kahan gave the inaugural lecture on Pain Management which was followed by a heated discussion on US Healthcare reform. Our College's Government Affairs chairperson, Carl Shapiro, and the AOA's healthcare lobbyist, Shawn Martin, presented contrasting perspectives for the policy changes we will all likely soon witness.

While this is a most challenging time in healthcare, it is a most exciting time for our organization. We have been working hard and it shows. Our membership is strong, surpassing 1,000 in May 2010. A growing team of dedicated members has been stepping up and are getting involved. But the story only begins there because we are not just about numbers. We have cultivated an atmosphere of a true brotherhood where people are eager to become involved. Our committees are growing because members are volunteering and asking where they can help. Not only are the numbers of people involved growing, we are branching out to new territory. Last year we officially established and launched the Government Affairs Committee headed by Carl Shapiro. We also have secured an Investment Manager to oversee our financial portfolio. Soon, we will create the New Physicians Council to help new physicians in practice to realize success.

The Student Conference was an overwhelming success. Resident membership attendance increased dramatically at this conference and the poster presentations were very well received. Several non-member physicians registered for the conference and then joined our organization on site.

I hope that everyone that was in Annapolis will plan to join us at the AOA Unified Convention this October in San Francisco. Our didactic sessions will be posted very soon for that meeting. The Mid Year for 2011 will be in the Phoenix metropolitan area and the dates and hotel will be announced very shortly.

S. Wilson $(\bowtie)$

American Osteopathic College of Physical Medicine and

Rehabilitation, Post Office Box 4, Phillipsburg, NJ 08865-0004,

USA

e-mail: stephanie.wilson@aocpmr.com 